\title{
Combined intracapsular cataract extraction and trabeculectomy with Severin five-loop posterior chamber intraocular lens*
}

\author{
J A COLEIRO
}

From the Department of Ophthalmology, Ninewells Hospital and Medical School, Dundee

\begin{abstract}
SUMmARY The efficacy and safety of a combined operation for cataract and glaucoma is established. This procedure of combined cataract extraction and trabeculectomy is taken one step further by the simultaneous insertion of the Severin intraocular posterior chamber lens implant. The results of treating 24 eyes in terms of control of glaucoma are discussed. Postoperative miotics may be required to improve stability of the implant, especially after delivery of the lens through a pupil rendered tight by long term preoperative miotic administration.
\end{abstract}

The association of cataract and glaucoma is a common problem in clinical practice. Attitudes differ on the management when lens opacities justify cataract surgery. The traditional approach has been to carry out filtering surgery followed by intracapsular lens extraction at some future date. ${ }^{\prime}$ With the universal adoption of trabeculectomy $\mathrm{y}^{23}$ as the drainage procedure of choice, several studies have confirmed the safety and good results of this procedure when combined with intracapsular cataract extraction. ${ }^{4-12}$

The universal difficulty has been to reconcile the desire for a secure cataract wound and at the same time obtain a filtering effect without the risk of a flat anterior chamber in the early postoperative period. Owing to the encouraging results of an earlier study without implantation,,$^{10}$ the procedure has been taken one step further by the insertion of a posterior chamber implant.

\section{Materials and methods}

Twenty-two patients ( 24 eyes) with open-angle glaucoma of a known duration of 2-20 years were admitted for cataract surgery between 1980 and 1984 . Seven were males and 15 were females of an elderly age group (56-94 years; mean age 78 years). Two patients had bilateral procedures.

*Presented to the Third Congress of the European Intraocular Implantlens Council, Harrogate, 11-14 September 1984.

Correspondence to Dr J A Coleiro, FRCS, Department of Ophthalmology, Ninewells Hospital and Medical School, Dundee DD1 9SY, Scotland.
The glaucoma was controlled preoperatively by timolol alone in six eyes, with a mean reading of 18 $\mathrm{mmHg}$, by several preparations in nine other eyes, and with additional oral carbonic anhydrase inhibitors in a further five. Four eyes were uncontrolled on maximal medical therapy. Four eyes had previous filtering surgery, two of which were uncontrolled.

The implant power was determined by keratometry and axisonics biometry. Implant powers used ranged from $16 \mathrm{D}$ to $24 \mathrm{D}$, with the $21 \mathrm{D}$ lens used in $70 \%$ of cases.

\section{SURGICAL TECHNIQUES (Fig. 1)}

General anaesthesia was employed for operations on 21 eyes, with the remaining three being carried out under local anaesthesia.

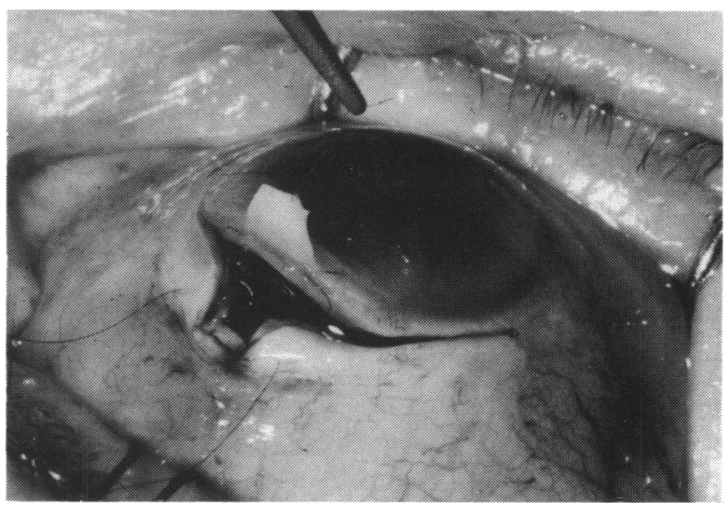

Fig. 1 Photograph of the completed section with the trabeculectomy and iridectomy. 
A fornix based conjunctival flap is reflected at the superior limbus. The underlying sclera at the limbus is lightly touched with bipolar diathermy to check bleeding points, mapping out the proposed region for the trabeculectomy. A $3 \times 2.5 \mathrm{~mm}$ half-thickness limbus-based scleral flap is fashioned by a diamond knife tapering slightly towards the cornea and reflected forwards. Prior to completing the trabeculectomy a corneoscleral groove is prepared. After completion of the excision of a $2 \times 2 \mathrm{~mm}$ inner corneoscleral lamellar flap by Vannas scissors the cataract incision is extended on both sides by inserting Troutman scissors through the trabeculectomy opening. A peripheral iridectomy is performed. Posterior synechiae from previous surgery or prolonged miotic therapy are gently divided. Several $10 / 0$ monofilament black nylon sutures are prepared, with a loop in the 12 o'clock position of the trabeculectomy flap to enable the assistant to open the wound without damaging the scleral edges. The lens is delivered by cryoextraction. Miochol (acetylcholine chloride 1\%, mannitol $3 \%$ ) is irrigated into the anterior chamber to produce miosis, followed by an air bubble.

A Severin five-loop lens implant (Iolab) is inserted into the posterior chamber by Clayman's forceps. The anterior superior loop of the implant is then anchored to the iris close to the iridectomy by transfixing with $10 / 0$ monofilament nylon.

The preplaced nylon sutures are locked tightly, with the least stable part of the incision on either side of the trabeculectomy flap secured by deep oblique sutures. The scleral flap is also sutured firmly with about five knots. All nylon ends are reversed and buried.

Air is aspirated from the anterior chamber and replaced by more Miochol or balanced salt solution (Alcon). The conjunctival flap is pulled down over the incision and sutured at either end by $8 / 0$ Dexon. A subconjunctival injection of $20 \mathrm{mg}$ Depo-Medrone (methylprednisolone acetate) is given into the lower fornix.

Postoperative miotics and topical steroid drops are administered for several weeks; the former are slowly withdrawn once implant stability is apparent.

\section{COMPLICATIONS}

Intraoperative. A ruptured capsule occurred in one eye; all cortical and capsular material was evacuated. Vitreous was lost on one occasion and the wound and anterior chamber were cleared by a Kaufman vitrector unit.

Some difficulty was encountered with pupillary dilatation in four patients on previous miotic therapy or surgical adhesions. Extraction of the cataract stretched the pupil which was reluctant to constrict fully to a hexagonal shape characteristic of a Severin implant, in spite of intracameral irrigation with Miochol.

Postoperative. Three patients had a shallow anterior chamber in the early postoperative period; in one instance choroidal detachments were observed. All settled by firm bandaging and oral acetazolamide without resort to inflating the anterior chamber. None resulted in loop contact with the cornea or evidence of any effect on the endothelium.

Two patients had a small hyphaema at the first dressing which cleared in three days. Four patients have a permanently semidilated $4 \mathrm{~mm}$ pupil resulting from sphincter damage by the lens delivery through a tight pupil, in spite of long-term postoperative miotics (pilocarpine $4 \%$ ). None of these implants have become dislocated, but this is possible should dilatation of the pupil become necessary for examination of the peripheral retina. Two eyes show a small amount of vitreous emerging between the implant loops into the anterior chamber. Cystoid macular oedema has not been observed in these eyes or the rest of this series.

The majority of operated eyes showed no significant degree of postoperative inflammation; the topical steroid drops were withdrawn altogether after six weeks. One eye developed a late inflammation of the implant (15 months) with large cellular precipitates adherent to both surfaces of the intraocular lens. These responded rapidly to a further subconjunctival depot steroid injection, with their complete dissolution within two weeks. The precipitates on the posterior surface were absorbed later than those situated anteriorly.

There was no case of pupillary blockage.

\section{Results}

Effects on intraocular pressure. There was an early pressure rise above $24 \mathrm{mmHg}$ in six eyes $(25 \%)$, but this settled within a few weeks or months. This may have been steroid-related.

The intraocular pressure was assessed at six and at 12 months (mean $15.7 \mathrm{mmHg}$ ) and the procedure determined as successful if the reading was $20 \mathrm{mmHg}$ or less. Twelve eyes $(50 \%)$ were controlled off all treatment, with five eyes $(20.8 \%)$ on pilocarpine. Three eyes $(12 \cdot 5 \%)$ required pilocarpine and timolol, with another three eyes controlled on timolol only. The glaucoma was uncontrolled in one eye $(4 \cdot 1 \%)$, which still requires multiple preparations.

Follow-up ranged from 12 months to five years. It appeared that, if the pressure was controlled at six months after operation, subsequent follow-up showed this to be retained.

Filtering blebs. Evidence of filtration was observed in 15 eyes $(62.5 \%)$, most showing a very shallow and 
diffuse bleb. No late bleb was present in nine eyes $(37 \cdot 5 \%)$. Five eyes with no bleb were controlled without therapy.

Visual results. Eighteen eyes (75\%) achieved a corrected acuity of $6 / 12$ or better. Four eyes (16.6\%) had significant recovery of useful vision in the range $6 / 18$ to $6 / 60$ due to various grades of senile macular degeneration. Two eyes $(8 \cdot 3 \%)$ had a postoperative vision of less than $6 / 60$ due to advanced senile macular disease and gross glaucomatous optic nerve damage.

The degree of astigmatism was less than 2 dioptres in all cases. The visual fields showed no deterioration.

\section{Discussion}

Should surgical management of both cataract and glaucoma be indicated, there are several options available. The glaucoma procedure may be performed before, after, or at the time of lens extraction. Prior glaucoma surgery may require the surgeon to modify the standard cataract incision by making a lateral or even an inferior incision. Inflammation and healing may possibly occlude a functioning bleb.

Simple cataract surgery alone can have a pressure lowering effect, but this is often only temporary. ${ }^{4}$

Combined procedures for glaucoma and cataract are currently being adopted as standard ophthalmological practice. The presence of an intraocular lens puts inevitable restrictions on medical therapy and any eventual glaucoma surgery. Most surgeons have therefore been reluctant to undertake the insertion of a lens implant at the same time as a combined operation. Some would even regard preexisting glaucoma as a relative contraindication to intraocular lens surgery. ${ }^{13}$ Prepupillary iridocapsular lens implantation has been undertaken after fistulising surgery by Binkhorst and Huber ${ }^{14}$ on eyes which had a functioning filtering bleb and normal levels of intraocular pressure. Amar ${ }^{15}$ carried out posterior chamber lens implantation with intracapsular cataract extraction three months after Lagrange sclerectomy, using a corneal section.

In recent years extracapsular cataract techniques have been used more often. Praeger found no appreciable difference between intracapsular and extracapsular removal of the cataract in terms of visual result or glaucoma control, ${ }^{12}$ Binkhorst and Huber ${ }^{14}$ found though an extracapsular technique to be more satisfactory.

An angle-supported Kelman anterior chamber lens has been proposed by Stiegler ${ }^{16}$ as being indicated for use with a combined procedure with the trabeculectomy sited at 10 or 2 o'clock, and he suggests that iris supported lenses of the Binkhorst type are contraindicated. Rigid anterior chamber lenses such as the Choyce Mk IX also have a place in combination with trabeculectomy, ${ }^{17}$ though in the long term elliptical pupils have been frequently observed. This lens can also be implanted in combination with cataract extraction in an eye which had a previous trabeculectomy.

A pupil supported lens of the Severin type is not recommended if the pupil is not capable of satisfactory constriction; an anterior chamber lens is to be preferred in this instance.

Montgomery and Gills ${ }^{18}$ have combined Shearing lens insertion with cyclodialysis with satisfactory results. Since this procedure does not depend on the pupillary sphincter for fixation and centration, the ruptured sphincter is less significant.

The additional surgical manoeuvres involved in the insertion of the Severin implant do not increase operative morbidity. Tight wound closure is essential for the prevention of a flat anterior chamber. The optical result is superior to that given by aphakic spectacles in the presence of glaucomatous field defects.

Phakic trabeculectomy has a long-term success rate of at least $75 \%$ in most series. This rate is reduced by simultaneous cataract extraction, and reduced further to about $50 \%$ if the procedure is extended to include lens implantation. ${ }^{10} 17$

I am indebted to the staff in the Medical Records Department of Ninewells Hospital for making available case records, and to Mrs Allene Gearce and Barbara Reynolds for typing the manuscript. My thanks are also due to Mr Cooper and Mr Orrock of the Medical Library, University of Dundee, for their help with searches and to Dr F Huber of Munich for the retrieval and translation of German publications; finally to Mrs Angela Ellingford and Mr Simon Scott for photographic assistance.

\section{References}

1 Bonavolonta A. Lens extraction after filtering surgery. In: Henkind P, ed. Acta: XXIV International Congress of Ophthalmology, San Franciso. Philadelphia: Lippincott, 1982; 1: 367-8.

2 Watson PG. Trabeculectomy. Trans Ophthalmol Soc UK 1969; 89: 523-6.

3 Watson PG, Barrett F. Effectiveness of trabeculectomy in glaucoma. Am J Ophthalmol 1975; 79: 831-45.

4 Witmer R, Rohen JW. Combined cataract glaucoma operation. Trans Ophthalmol Soc UK 1976; 96: 256-61.

5 Jerndal $T$, Lundstrom $M$. Trabeculectomy combined with cataract extraction. Am J Ophthalmol 1976; 81: 227-31.

6 Johns GE, Layden WE. Combined trabeculectomy and cataract extraction. Am J Ophthalmol 1979; 88: 973-81.

7 Edwards RS. Trabeculectomy combined with cataract extraction: a follow-up study. Br J Ophthalmol 1980; 64: 720-4.

8 Luntz MH, Berlin MS. Combined trabeculectomy and cataract extraction. Trans Ophthalmol Soc UK 1980; 100: 533-41.

9 Romem M, Isakow I, Dolev Z. Simultaneous trabeculectomy and cataract extraction. Br J Ophthalmol 1982; 66: 250-2.

10 Coleiro JA. Combined cataract extraction and trabeculectomy. S Afr Arch Ophthalmol 1982; 9: 15-9.

11 Hesse W, Bartl G. A follow-up study of combined cataract/ trabeculectomy operation. Klin Monatsbl Augenheilkd 1982; 181: 367-9. 
12 Praeger DL. Combined procedure: subscleral trabeculectomy with cataract extraction. Ophthalmic Surg 1983; 14: 130-4.

13 De Heer LJ. Glaucoma as a problem in intraocular lens implantation. Doc Ophhthalmol 1980; 49: 337-46.

14 Binkhorst CD, Huber E. Cataract extraction and intraocular lens implantation after fistulising glaucoma surgery. J Am Intraocul Implant Soc 1981; 7: 133-7.

15 Amar L. Glaucoma and cataract: Amar posterior chamber implant. Bull Mem Soc Fr Ophthalmol 1982; 94: 283-4

16 Stiegler G. Combined trabeculectomy: intracapsular cataract surgery with intraocular lens implantation. Klin Monatsbl Augenheilkd 1981; 179: 456-60.

17 Galin MA, Ostbaum SA, Asano Y, Maghraby A. Trabeculectomy, cataract extraction, and intra-ocular lens implantation. Trans Ophthalmol Soc UK 1985; 104: 570-3.

18 Montgomery D, Gills JP. Extracapsular cataract surgery, lens implantation and cyclodialysis. Ophthalmic Surg 1980; 11: 343-7.

Accepted for publication 9 December 1985. 